\title{
Smart irrigation and plant monitoring system using Arduino
}

\author{
Mr. Shubham P.Bhujba ${ }^{1}$, Mr. Sohil S. Hendre ${ }^{2}$, Mr. Digvijay S. Mohite ${ }^{3}$, Prof. Alka Kulkarni ${ }^{4}$ \\ Student, Computer Dept., KJEI'S Trinity Academy of Engineering, Pune, India ${ }^{1,2,3}$ \\ Professor, Computer Dept., KJEI'S Trinity Academy of Engineering, Pune, India ${ }^{4}$
}

\begin{abstract}
Agriculture helps to meet the basic needs of human and their civilization by providing food, clothing, shelters, medicine and recreation. Agriculture provides food, feed, fiber, fuel, furniture, raw materials and materials for and from factories; provides a free fare and fresh environment, abundant food for driving out famine; favors friendship by eliminating fights. Crops ranks sixth among pulses production in world and major legume crop. Average world production of crops is at 3.0 million tons in the last six years (2000-05). The area under cultivation is stagnant at 4.5 million hectares in the same period. Crops are drought resistant and can be grown in areas with less than $650 \mathrm{~mm}$ annual rainfall. World production of crops is estimated at $46,000 \mathrm{~km}^{2}$. About $82 \%$ of this is grown in India. Hence it is necessary to develop android application for crops crop. It is beneficial for farmer to have all information related to crops crop. This app will contain crop information and disease related to crop.
\end{abstract}

Keywords: Climate, Sensors, climate, agricultural productivity, crop production, prediction, Internet of Things.

\section{INTRODUCTION}

In India, food grain production increased almost four folds from about 50 million tons at independence to more than 220 million tons in 2005 through green revolution. Although variation_in the performance of individual crops and country total food grain production maintained a_growth of $2.7 \%$ per annum, this kept ahead of population growth at about $2.2 \%$ per annum. Through white revolution, milk production increased from 17 million tons at independence to 69 million tons (1997-98). Through blue revolution, fish production rose from 0.75 million_tones to nearly 5.0 million tons during the last five decades. Through yellow revolution, oil seed_production increased 5 times (from 5 million tons to 25 million tons) since independence._Similarly, the egg production increased from 2 billion at independence to 28 billion, sugarcane_production from 57 million tons to 276 million tones, cotton production from 3 million bales to_14 million bales which shows our sign of progress. India is the biggest producer of fruits in the world wide area. In future, agriculture_development in India would be guided not only by the compulsion of improving food and nutrition nal security, büt also by the concerns for environmental protection, sustainability and_profitability. By following the General Agreement on Trade and Tariff (GATT) and the liberalization process, globalization of markets would call for competitiveness and efficiency of_agricultural production. Agriculture will facing on the ecological, global_climate, economic equity, energy and employment fronts in the years to come.

\section{LITERATURE SURVEY}

\section{Agricultural Production Output Prediction Using Supervised Machine Learning Techniques.[1]}

Author: Md. Tahmid Shakoor, Karishma Rahman, Sumaiya Nasrin Rayta, Amitabha Chakrabarty

Description: The research suggests area based beneficial crop rank before the cultivation process. It indicates the crops that are cost effective for cultivation for a particular area of land. To achieve these results, we are considering six major crops which are Aus rice, Aman rice, Boro rice, Potato, Jute and Wheat. The prediction is based on analyzing a static set of data using Supervised Machine Learning techniques. This static dataset contains previous years' data taken from the Yearbook of Agricultural Statistics and Bangladesh Agricultural Research Council of those crops according to the area. The research has an intent to use Decision Tree Learning- ID3 (Iterative Dichotomiser 3) and K-Nearest Neighbors Regression algorithms.

Title: Crop Selection Method Based on Various Environmental Factors Using Machine Learning.[2]

Author: Nishit Jain, Amit Kumar, Sahil Garud, Vishal Pradhan, Prajakta Kulkarni 
Vol. 8, Issue 2, February 2019

Description: we suggest a method which would help suggest the most suitable crop(s) which will maximize yield by summing up the analysis of all the affecting parameters. These affecting parameters can be economical, environmental as well as related to yield in nature. Economic factors such as market prices, demand etc. play a very significant role in deciding a crop(s) as does the environmental factors such as rainfall, temperature, soil type and its chemical composition and total produce. Therefore, it's necessary to design a system taking into consideration all the affecting parameters for the better selection of crop(s) which can be grown over the season.

\section{A Scalable Machine Learning System for Pre-Season Agriculture Yield Forecast.[3]}

Author: Igor Oliveira, Renato L. F. Cunha, Bruno Silva, Marco A. S. Netto

Description: Yield forecast is essential to agriculture stakeholders and can be obtained with the use of machine learning models and data coming from multiple sources. Most solutions for yield forecast rely on NDVI (Normalized Difference Vegetation Index) data, which is time-consuming to be acquired and processed. This system provides significantly useful results by the exempting the need for high-resolution remote-sensing data and allowing farmers to prepare for adverse climate influence on the crop cycle. In our studies, we forecast the soybean and maize yields for Brazil and USA, which corresponded to $44 \%$ of the world's grain production in 2016. Results show the error metrics for soybean and maize yield forecasts are comparable to similar systems that only provide yield forecast information in the first weeks to months of the crop cycle.

Machine learning approach for forecasting crop yield based on climatic parameters.[4]

Author: S.Veenadhari, Dr. Bharat Misra, Dr.CD Singh

Description: In the present study a software tool named 'Crop Advisor' has been developed as an user friendly web page for predicting the influence of climatic parameters on the crop yields.C4.5 algorithm is used to find out the most influencing climatic parameter on the crop yields of selected crops in selected districts of Madhya Pradesh. This software provides an indication of relative influence of different climatic parameters on the crop yield, other agro-input parameters responsible for crop yield are not considered in this tool, application of these input parameters varies with individual fields in space and time.

\section{PROPOSE SYSTEM}

In Proposed system we are analysing the information security of authorized user. So, in this paper the User can register the Application and registration is successful the login the application. Similarly Admin can register the application and registration is successful then login the application. Using hardware it will fetch and Analysis the information. And using Wi-Fi it will Transmit the information of User.

\section{IV.SYSTEM ARCHITECTURE}

Following diagram is our system's architecture diagram:

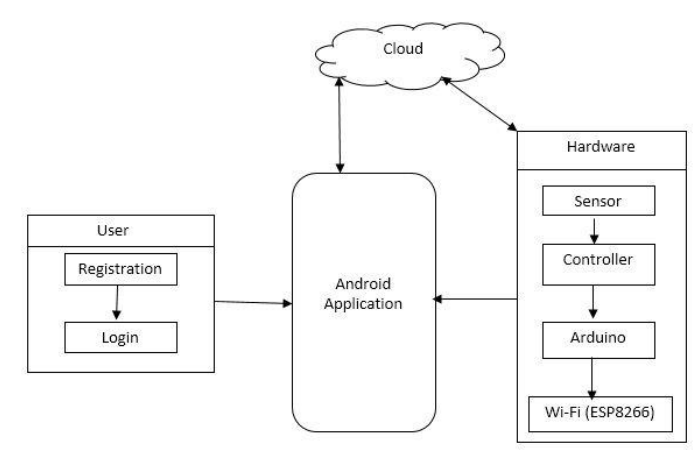

Figure 1: system architecture

In system architecture user has a android application then user can register the application. Registration is successful then login the application . this information is save in cloud. So, using Hardware it will fetch and analysis the value from hardware and using Wi-Fi it will transmitted to application. 


\section{IJARCCE}

\section{OBJECTIVE}

To help farmer about crop information.

To make eco-friendly android application.

\section{VI.METHODOLOGIES}

User can register the application then registration is successful then login the application. Then using Wi-Fi interfacing it can connect to the hardware fetch values from hardware and analysis the value. From hardware. And display the result.

Sensor connection :-in that sensor can sense the hardware value and analysis those hardware values.

Controller connection :- Arduino can transmit the value using Wi-Fi.

Wi-Fi Connection :- In Wi-Fi connection we use ESP8266 Wi-Fi. So ,Using Wi-Fi it can send the hardware values to User.

\section{MODULE}

\section{Software Modules:}

1. Registration

2. Login

3. Dataset Generation

4. Wi-Fi Interfacing

5. Fetch Values from $\mathrm{H} / \mathrm{W}$

6. Analysis of $\mathrm{H} / \mathrm{W}$ values

7. Result display

\section{Hardware Modules:}

1. Sensor connection

2. Controller connection

3. Wi-Fi Connection

\section{CONCLUSION}

We are implementing a decision support system for monitoring different farm activities. Using Monitoring information farmer can access or control his farm activities. It helps to increase a Crop yield and contain crop information and disease related to crop. Our system is cost effective and user friendly.

\section{REFERRENCES}

[1] W.Lizhe, Jie Tao, M.Kunze, A.C. Castellanos, D.Kramer, and W.Karl,“Scientific Cloud Computing: Early Definition and Experience,” In HPCC, vol. 8, pp. 825-830. Sep 2008.

[2] P.K.Paul and M.K.Ghose, "Cloud computing: possibilities, challenges and opportunities with special reference to its emerging need in the academic and working area of Information Science," In Procedia Engineering, vol. (23), pp.2222-2227, Jan 2012.

[3] Kandukuri, Balachandra Reddy, and Atanu Rakshit, "Cloud security issues," InServices Computing, 2009. SCC\&\#39;09. IEEE International Conference on IEEE, pp. 517-520, Sep 2009.

[4]L. Adleman, "Molecular computation of solutions to combinational problems".American Association for the Advancement of Science, pp.1021$1024,1994$.

[5] Rachna.A, and Anshu.P, "Maintaining Data Confidentiality and Security over Cloud: An Overview", International Journal of Engineering Research and Applications (IJERA), Vol. (4), pp.1922-1926, July 2013.

[6] D.Sureshraj and Dr.V.Murali Bhaskaran, Automatic DNA Sequence Generation for Secured Effective Multi-Cloud Storage, Journal of Computer Engineering (IOSR-JCE), vol.15, pp. 86-94, Nov-Dec 2013. 